Article

\title{
Novel Composite Materials for Lake Restoration: A New Approach Impacting on Ecology and Circular Economy
}

\author{
Miltiadis Zamparas ${ }^{1, *(\mathbb{D})}$, Grigorios L. Kyriakopoulos ${ }^{2}\left(\mathbb{D}\right.$, Marios Drosos ${ }^{3}$, Vasilis C. Kapsalis ${ }^{4}(\mathbb{D}$ \\ and Ioannis K. Kalavrouziotis ${ }^{1}$ \\ 1 School of Science and Technology, Hellenic Open University, Parodos Aristotelous 18, 26335 Patras, Greece; \\ ikalabro@eap.gr \\ 2 Electric Power Division, Photometry Laboratory, School of Electrical and Computer Engineering, \\ National Technical University of Athens, 15780 Athens, Greece; gregkyr@chemeng.ntua.gr \\ 3 Institute of Resource, Ecosystem and Environment of Agriculture (IREEA), Faculty of Biology and \\ Environment, Nanjing Agricultural University, 1 Weigang Road, Nanjing 210095, China; \\ drosos.marios@gmail.com \\ 4 School of Mechanical Engineering, Industrial Management and Operations Research Sector, \\ National Technical University of Athens, 9 Heroon Polytechniou Street, 15780 Athens, Greece; \\ bkapsal@mail.ntua.gr \\ * Correspondence: mzamparas@upatras.gr
}

Received: 27 February 2020; Accepted: 18 April 2020; Published: 22 April 2020

check for updates

\begin{abstract}
The purpose of this study is to promote a new way of application composite materials to restore eutrophic waters. A new sustainable way of application is based on the "teabag" method, in which materials were placed in water-permeable bags and immersed in the water column in order to sorb phosphate- one of the main contributory element for the eutrophication problem. Particularly, the two composites materials of Phoslock ${ }^{\mathrm{TM}}$ (lanthanum-modified bentonite, LMB) and Bephos ${ }^{\mathrm{TM}}$ (Fe-modified bentonite, $\mathrm{f}-\mathrm{MB}$ ) were tested and bench-scale batch experiments were employed to investigate their sorption efficiency in the forms of slurry and teabag. The adsorption kinetics and the relevant adsorption isotherms were deployed, while the effect of the materials on turbidity and their aging were also investigated. Experimental results showed that Phoslock ${ }^{\mathrm{TM}}$ and Bephos ${ }^{\mathrm{TM}}$ (as teabag), being applied at initial concentration range: $0.05-5 \mathrm{mg} / \mathrm{L}$, they sustained a maximum adsorption capacity of $7.80 \mathrm{mg} / \mathrm{g}$ and $25.1 \mathrm{mg} / \mathrm{g}$, respectively, which are considered sufficient rates for $\mathrm{P}$ concentrations reported at natural aquatic ecosystems. At the same time this new method did not cause turbidity in the water column, since the material was not released into the water, thus, preventing potential harmful consequences for the living organisms. Moreover, the "teabag" method prevents the material to cover the lake bottom, avoiding the phenomenon of smothering of benthos. By teabag method, the materials can be collected for further applicability as soil improver or crops fertilizer. Finally, it was argued that the possibility to recycle LMB and f-MB materials for agricultural use is of paramount importance, sustaining also positive impacts on sustainable ecology and on the routes of circular economy $(\mathrm{CE})$.
\end{abstract}

Keywords: LMB; f-MB; eutrophication; lake restoration; teabag method; natural aquatic ecosystems; circular economy

\section{Introduction}

The steady increase of global population growth and the increased nutrition needs are directly related to the intensification of agricultural production. While seafood meets only a small portion of 
human nutrition the ongoing global population necessitates the agricultural intensification, the excess use of fertilizers in a global level of reference and it is, subsequently, causing eutrophication incidences. Indeed, at the aqueous environments, pollution is the main cause of eutrophication, which is forming harmful algal blooms, decrease of dissolved oxygen to water sources and endanger of local ecosystems [1-3], especially in terms of socio-economic and technological valuation [4,5].

The restoration of eutrophic waters in the relevant literature has been focused on reducing nutrients' loading from the catchment, including runoff from agricultural soils. Catchment remediation is materialized by confining stock access to aquifers, thus, developing wide riparian buffer zones and constructed wetlands on the mainstream routes [6-8].

However, under eutrophic conditions the recovery of the water bodies from heavy internal loads remains stagnate. Under eutrophic conditions phosphorus release from the sediment into aquifers remains persistent and it prevents recovery of the ecosystem despite reduced external loading [9]. Notably, the phenomenon of terrestrial eutrophication is mainly reported at aqueous bodies or soil environments [10]. At this study the terms of eutrophication, Bephos ${ }^{\mathrm{TM}}$, and Phoslock ${ }^{\mathrm{TM}}$ have been introduced, based on the relevant literature production.

Bephos $^{\mathrm{TM}}$ (thereafter named as: "f-MB", Fe-modified bentonite) is a novel low-cost composite material of embedding $\mathrm{Fe}, \mathrm{Cu}$ ions and humic acid while exploiting interlayer space of natural bentonite [11,12].

Moreover, Phoslock ${ }^{\mathrm{TM}}$, or lanthanum-modified bentonite (thereafter named as: "LMB"), is a phosphorus locking technology being structured by elemental lanthanum in a bentonite clay matrix in order to sorb and inactivate soluble reactive phosphorus [13,14]. Today, LMB is being increasingly used for: first, to strip P from the water column and, secondly, to prevent $\mathrm{P}$ release from sediment when applied as active capping material [15-18].

This pluralistic approach can unveil remediation strategies to reduce the release rate of nutrient flux by blocking the sedimental release of P. Due to the significance of this research field, a detailed literature review was deployed under the following three classifications: (a) pH-based researches (b) On-site/field applications of selected composite materials, and (c) Cyanobacteria-Aquatic organisms/environment-Agricultural contexts, was structured, respectively.

The aforementioned classifications were decided due to the flexibility of co-evaluating similar research approaches offered, thus, enabling readers to be better familiarized with a wide spectrum of different remediation techniques and, then, to scrutinize and select those remediation techniques, which can be reproduced at similar research/experimental, or in-field settings worldwide. The common functionality of such techniques is the effectiveness of technologies to stabilize sediments, the minimization of both re-suspension and transport, and the subsequent control of nutrients transport into overlying waters.

In the relevant literature the investigation of nutrient circulation in water sources is not new. It is indicatively noted that there have been developed endeavors under which feed composition scenarios of Baltic herring were used as feed raw material production and transportation, thus resulting in circulation of nutrients in the Baltic Sea area. The main factors of consideration were that of: changes at consumers behavior of people and their preference to specific sea feedstock, as well as the high uncertainty caused by sparse consumption data of fishing fuel and by the vague consideration of local fish farming impacts and feasible assessment of environmental impacts [19]. Another issue of environmental significance is that of eutrophication. It is indicatively noted that in the relevant literature experiments were carried out to examine the effect of two ornamental plants planted to environmental remediation and the improvement water quality caused by the excessive quantities of the eutrophication materials of phosphorus and organic in urban riverway sewages [20].

In managing the load and the fate of nutrients at rivers sediment, it is noteworthy the creation of vertical movement of sedimental clays with time due to intensive bioturbation. This vertical movement accelerates retention capacity of phosphorus and nitrogen at the subsurface sediment, thus, supporting the remediation of polluted river sediment. In this framework, the effective control of all 
the total and soluble nitrogen and phosphorus can be determined by intermittent aeration whereas bioturbation is not effecting on phosphorous control efficiency, and has negative influence on nitrogen removal [21].

Except for rivers and seas, the main research production on nutrients fate has been focused on ponds and lakes [22]. At these water sources the utility of LMB application is mainly attributed to be a suitable agent for the stable removal of soluble phosphorus from water body, since soluble phosphorus is mainly determining algae bloom [17,23]. Particularly, Bishop and Richardson [22] studied the application of LMB to irrigation ponds and monitored the post-treatment of nutrients' loading and blooms of chronic cyanobacteria. Concomitantly, it is crucial to determine the mitigation of sediment phosphorus in shifting nutrient ratios and changing the composite profile of algal assemblage [22]. Moreover, Bishop et al. [13] stressed out the decisive role of a phosphorus binding technology and its impacting on algae assemblage composition and water quality parameters. Furthermore, in an earlier study Robb et al. [18] denoted that laboratory trials demonstrated the effectiveness of LMB to bind sediment released $\mathrm{P}$ using less than a millimeter thickness of clay, especially at excessive fluvial blooms of blue-green algae during the summer months.

In a similar study, a follow-up research was conducted of phosphorus management with LMB in an eutrophic, shallow swimming lake in Germany, showing the phenomenon of excess phosphorous concentrations as a result of human-generated nutrients [24]. The role of external phosphorous inputs from water-flow-and possibly other external sources-was also discussed upon the water treatment of two lakes in North America. The promising results of water treatment by LMB enabled researchers to plan this application in Quebec lake and in several other provinces of the nearby area [25], as well as the meta-analysis of water quality and macrophytes' profile in 18 lakes, upon application of LMB [26]. Such P-control can support rapid ecological recovery through data availability in monitoring lakes and variables, especially closer to the application dates. The main reported parameters are the concentration of summer chlorophyll-a and the Secchi disk depths upon LMB application [26]. Specifically, these authors stated that aquatic macrophyte responses have been significantly varied among different lakes tested, while improving water quality and macrophyte community [26].

LMB has been extensively studied in the relevant literature [27-29]. Specifically, LMB can be effectively applied to control sediment P-release under anaerobic conditions, under a proposed model involving the utility of P-capping agents at lakes' environmental remediation, achieving cost-effectiveness and reducing those non-target effects; through applying multiple smaller doses comparing to a single high dose and releasing sedimentary $\mathrm{P}$ under aerobic conditions comparing the statement that significant $\mathrm{P}$ release can be occurred with persisting prolonged anaerobic conditions [30]. Besides cases where $\mathrm{PO}_{4}-\mathrm{P}$ and total phosphorus (TP) are not statistically different among water samples treated, the positive potential role of the modified clay remains unclear and questionable in practice [31]. Another result of LMB concentration increase is the conductivity increase and turbidity decrease, due to rapid settlement [29,32].

It has been also proven that iron redox cycle plays a primary role to control the mobility of sedimentary P. Therefore, it is critical to better understand the ways of the highly capping-efficient LMB could immobilize sedimentary P by altering the cycling of Fe redox-coupled P [33,34]. Considering that the demand for fertilizers is increasing worldwide, contrarily to the global phosphate supply shortage [35], since P-rich fertilizers are certain determinants of eutrophication through excessive disposal in water bodies.

Pre- and post-treatments of LMB were analyzed upon the parameters of: $\mathrm{pH}$, total suspended solids, conductivity, turbidity, color and phosphate concentration; accomplishing 95\% removal of phosphate anions $\mathrm{PO}_{4}{ }^{3-}$, while $\mathrm{LMB}$ application did not cause $\mathrm{pH}$ change at the final effluent [27], while such pre- and post- treatment of LMB showed that the $\mathrm{pH}$ of the treated water returns closer to the neutral level within days of LMB application [28]. Moreover, the application of LMB to bind soluble reactive phosphorus and to release of nutrients showed the release of small quantities of ammonium, but it did not affect oxygen saturation [29] and $\mathrm{pH}$ [30]. At another laboratory-tested analysis the 
application of LMP revealed that monovalent phosphate anion of H2PO4- showed high affinity for the adsorbent surface, while activation energy was lower at a higher $\mathrm{pH}$, since the loss of adsorption sites at higher $\mathrm{pH}$ is unaffected by ionic strength [16].

In summarizing the main advantages of on-site and pilot-scale composite materials' application, it is signified that LMB can result in the quick and effective removal of soluble phosphorus from eutrophic water bodies, the low levels of the soluble phosphorus at water bodies in the long-run [23], the high removal rates of dissolved phosphorus (DP) concentrations at various types of water bodies [28], the short term compositional alterations in sediment and elementary P-fractions on sediment cores sampled at different times before and after LMB application to a man-made reservoir, where LMB can bind decreasingly P mobile present upon increasing the height of top sediment, while no affecting the sediment P-fractions [36], as well as promising LMP applicability in alleviating terrestrial eutrophication due to building materials' contemplated, along with the necessity of developing calculating methods of the eutrophication potential [10]. In a similar study, Burska et al. [37] evaluated the possibility of using water-permeable nonwovens bags as P-sorbent carriers. Such a bag was filled with the sorbing material and when placed in the water column, sorbent present in the bag reduced orthophosphate $\left(\mathrm{PO}_{4}{ }^{3-}\right)$ concentration in the water due to the water inflow into the bag. Specifically, for three synthetic sorbents used in the study the effectiveness of $\mathrm{PO}_{4}{ }^{3-}$ removal raised with rising temperature and the initial $\mathrm{PO}_{4}{ }^{3-}$ concentration. Moreover, the addition of probiotic organisms favored the reduction of $\mathrm{PO}_{4}{ }^{3-}$ concentration, while the addition of another synthetic sorbent caused the $\mathrm{pH}$ decrease even to $\mathrm{pH}=6.45$.

In summarizing the approached of environmental remediation through management of aquatic eutrophication and aquatic ecosystems they are noteworthy: the in situ sediment remediation using the modified clays of LMB and modified zeolite, to control fluvial nitrogen and phosphorus sedimental loading and intermittent aeration [21], the application of LMB to control the high transparency and the low levels of soluble phosphorus at lakes from polluted inflows to lakes by domestic and agriculture mixed wastewater [23], where LMB-applied sinks to the lake bottom intercepts the upward flux of internal load from sediment $P$ release [25]. Such P management can: increase the suspension of $P$ mass [26,30]; decrease the intensity of mineralization processes, prevent large algal and cyanobacterial blooms, enhance the swimming and the recreation uses for lakes [24]; decrease the levels of water column total $\mathrm{P}$, causing a shift form mobile sediment $\mathrm{P}$ to residual fractions [22]; control eutrophication while mitigating cyanobacterial nuisance [31]; advance novel technologies to inactivate phosphorus and achieve improved water quality by developing dense submerged macrophytes beds [29].

The challenging issues of our research study are the selection of innovative materials in proper conditioning, which can be introduced as "teabag" into the water column, to absorb the available phosphorus remaining in the water column without creating a risk for the ecosystem. The necessary quantities of material utilized in the form of slurry should be accurately calculated based on the potentially bioavailable mobile $P$ of the sediment in the water column, and its external flows can be adsorbed by the proposed method of "teabag". In addition, this study was focused on challenges and methodologies to improve P use efficiency and sustainability in the environment. In this framework, technologies for the removal of P-containing compounds from water using functional sorbents should mainly regard surface properties for capture and removal, through recycling the LMB and $\mathrm{f}-\mathrm{MB}$ materials as alternative soil fertilizers. Specifically, the challenges regarding the application of LMB and $\mathrm{f}-\mathrm{MB}$ were related to their properties as well as the potential utility of these modified clays as fertilizers by implementing the teabag method.

\section{Materials and Methods}

\subsection{Materials}

Lanthanum-modified bentonite (LMB), was the material of anthropogenic origin developed by the Land and Water Division of Australia's CSIRO (Commonwealth Scientific and Industrial 
Research Organization) [16]. Fe-modified bentonite (f-MB), was synthesized as it is reported in Zamparas et al. [12].

\subsection{Batch Experiments}

\subsubsection{Sorption Capacity}

The preparation of phosphate sorption experiments was described by Zamparas et al. [38]. The determination of adsorption isotherms was made by batch equilibration of $0.02 \mathrm{~g}$ of each bentonite sample (as teabag method and as a slurry) with $50 \mathrm{~mL}$ of aqueous phosphate solutions (Figure 1). To this end the initial concentrations fall at a wide range of P: 0.05 up to $5 \mathrm{mg} / \mathrm{L}$. The experiments were conducted at room temperature $\left(25 \pm 1^{\circ} \mathrm{C}\right)$ and $\mathrm{pH} 7$ for $3 \mathrm{~h}$. The authors decided to perform experiments at $\mathrm{pH}$ value equal to 7 since this value is within the $\mathrm{pH}$ range of eutrophic natural waters. After reaching equilibration, then centrifugation of the suspension ( $4500 \mathrm{rpm}$ for $15 \mathrm{~min}$ ) was applied for its separation and the molybdate blue spectrophotometric method was applied to measure the concentration in supernatant (ce) [39] by a Lambda 25 UV-Vis spectrophotometer (Perkin-Elmer, Germany) of sensitivity threshold $0.01 \mathrm{mg} \mathrm{PO}_{4}^{-3} / \mathrm{L}$.

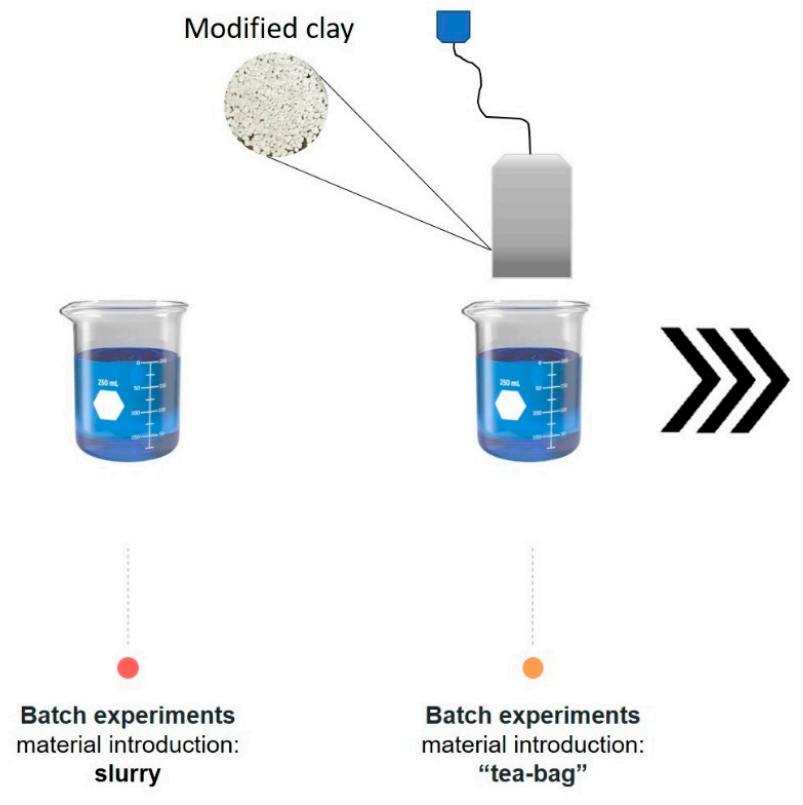

(a)

(b)

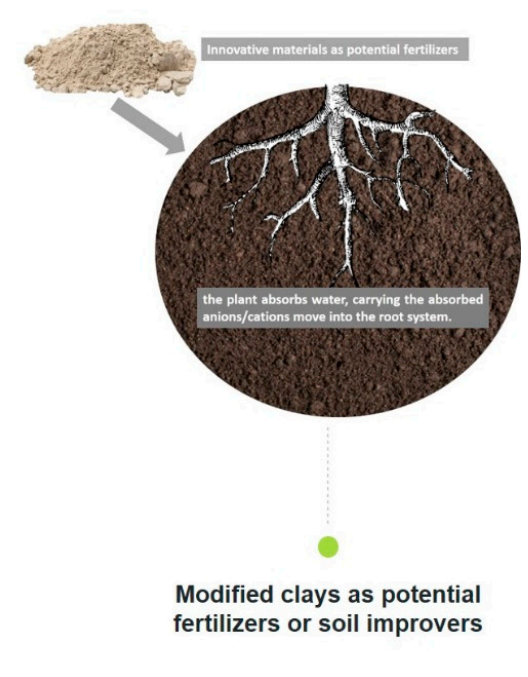

(c)

Figure 1. (a,b) Schematic diagram of the setup of the batch experiments and (c) potential future use of materials as fertilizers or soil improvers.

The adsorbed phosphate (qe) was quantified by the difference in between initial (co) and equilibrium concentration values. Moreover, blank samples (no adsorbent included) were perpetrated and monitored as control. All experiments were carried out in triplicates.

\subsubsection{Sorption Kinetics}

Sorption kinetic data of phosphate on the two modified bentonites (as teabag method and as a slurry) at contact times ranging between $15 \mathrm{~min}$ and $240 \mathrm{~min}$ were studied, while the other experimentally optimized conditions were set as: $\mathrm{pH} 7$, phosphate concentration $0.1 \mathrm{mg} / \mathrm{L}$, adsorbent dose $0.02 \mathrm{~g}$ and $25 \pm 1{ }^{\circ} \mathrm{C}$ temperature. Given that $\mathrm{PO}_{4}-\mathrm{P}$ concentrations close or greater than $0.1 \mathrm{mg}$ $\mathrm{P} / \mathrm{l}$ are generally perceived to be sufficiently high to result in freshwater eutrophication, this initial concentration was chosen to simulate the $\mathrm{P}$ concentrations presenting in natural eutrophic waters. Phosphate concentration was measured as described in Section 2.2.1. 


\subsubsection{Effect of LMB and f-MB on Turbidity}

To access the effect on turbidity $0.5 \mathrm{~g}$ of LMB and $\mathrm{f}-\mathrm{MB}$ were added to $500 \mathrm{ml}$ of purified water Milli-Q. Turbidity (NTU) was measured regularly over $6 \mathrm{~h}$ in still water, i.e., a maximum undisturbed settling rate. NTU decay is described by an exponential decay 2 function (OriginPro8). For LMB and $\mathrm{f}-\mathrm{MB}$ application as a slurry, $0.5 \mathrm{~g}$ of LMB and $\mathrm{f}-\mathrm{MB}$, respectively, were dispensed into a $50 \mathrm{~mL}$ tube and purified water Milli-Q was added until the $20 \mathrm{~mL}$ mark on tube, which was then vortexed for $1 \mathrm{~min}$ to hydrate the bentonite granules. This slurry was then added to a beaker, rinsing out the remaining mixture from the tube with $\leq 5 \mathrm{~mL}$ purified water from a squeeze bottle.

\subsection{Adsorption Efficiency}

The adsorption capacity of phosphate by the modified adsorbents can be calculated at the following equation 1 , being fully presented at our previous research study $[7,38]$.

$$
q_{t}(m g / g)=\frac{\left.\left(C_{0}-C_{t}\right) * V / 1000\right)}{W}
$$

where qt is the adsorption capacity of $\mathrm{PO}_{4}-\mathrm{P}$ on the adsorbent at time $\mathrm{t}, \mathrm{c}_{0}$ is the initial $\mathrm{PO}_{4}-\mathrm{P}$ concentration $(\mathrm{mg} / \mathrm{L}), \mathrm{c}_{t}$ is the equilibrium concentration of $\mathrm{PO}_{4}-\mathrm{P}$ in solution at time $\mathrm{t}(\mathrm{mg} / \mathrm{L}), \mathrm{V}$ is the volume of the working solution $(\mathrm{mL})$, and $\mathrm{W}$ is the weight of the adsorbent used $(\mathrm{g})$.

Two isotherm models including Langmuir and Freundlich as described in Equations (2) and (4) can express most of the adsorption data:

$$
q_{e}=\frac{b q_{m} C_{e}}{1+b C_{e}}
$$

$\mathrm{C}_{\mathrm{e}}(\mathrm{mg} / \mathrm{L})$ and $\mathrm{q}_{\mathrm{e}}(\mathrm{mg} / \mathrm{g})$ are the equilibrium adsorbate concentrations in the aqueous and solid phases. Here, $\mathrm{q}_{\mathrm{m}}(\mathrm{mg} / \mathrm{g})$ is the maximum adsorption capacity and $\mathrm{b}$ is the Langmuir adsorption.

Based on the Langmuir equation, a dimensionless constant, i.e., called separation factor $R_{L}$, (dimensionless entity) can predict the favorably or unfavorably sorption system [40], Equation (3), taken values $(0,1)$ or higher than 1 , respectively [41]. Moreover, the values of 0 and 1 correspond to irreversible or linear adsorption, respectively.

$$
R_{L}=1 /\left(1+b C_{0}\right)
$$

The Freundlich isotherm model is measured at the following exponential equation between the solute concentration values on the heterogeneous surface and in the liquid.

$$
q_{e}=K_{f} C_{e}^{1 / n}
$$

$K_{f}$ and $n$ are the Freundlich equilibrium and adsorption constants, respectively, while the reciprocal value, $1 / n$, indicates the adsorption intensity.

\subsection{Leaching Experiment}

A sample (50 mg) of f-MB was suspended in $50 \mathrm{~mL}$ of milli-Q $\mathrm{H}_{2} \mathrm{O}$ at $\mathrm{pH} 7$ for 70 days incubation in shielded vials under constant steering. The suspension was filtered through Whatman 42 filters, acidified using concentrated $\mathrm{HCl}$ to a final $\mathrm{pH} 3.5$, and $\mathrm{Al}, \mathrm{Cu}$ and $\mathrm{Fe}$ in the acidified filtered solution was measured by a Perkin Elmer AA700 Atomic Adsorption Spectrometer (AAS) in the graphite furnace mode. To investigate the possible leaching of $\mathrm{Al}, \mathrm{Cu}$ and $\mathrm{Fe}$ in the soil medium, the same experiment was repeated using 250 ppm soil humic acid (SHA) in milli-Q at pH 7 solution for 70 days incubation. The SHA is a well characterized material named as SHA3 [42] and Sparental HA [43] in previous studies. Finally, $250 \mathrm{ppm}$ of SHA solution in milli-Q at $\mathrm{pH} 7$ after 70 days incubation was filtered through Whatman 42 and acidified. $\mathrm{Al}, \mathrm{Cu}$ and Fe where measured by AAS to set as control. 
The values are reported in Table 1. A leaching experiment carried out for 70 days incubation revealed no leaching of $\mathrm{Al}$ or $\mathrm{Cu}$ and only an insignificant Fe leaching $(0.03 \mathrm{~g} / \mathrm{kg})$ in water. On the contrary, in soil solution no leaching of $\mathrm{Al}$ or Fe was observed and only $\mathrm{Cu}$ leaching was reported (Table 1).

Table 1. Al, $\mathrm{Cu}$ and Fe ppm measured by AAS after 70 days incubation.

\begin{tabular}{cccc}
\hline & SHA & SHA + f-MB & $\mathbf{H}_{\mathbf{2}} \mathbf{O}+\mathbf{f}-\mathbf{M B}$ \\
\hline $\mathrm{Al}$ & $3.80 \pm 0.01$ & $3.02 \pm 0.01$ & - \\
$\mathrm{Cu}$ & - & $6.35 \pm 0.01$ & $0.01 \pm 0.01$ \\
$\mathrm{Fe}$ & $2.13 \pm 0.01$ & $2.10 \pm 0.01$ & $0.03 \pm 0.01$ \\
\hline
\end{tabular}

Yet, for an application of 5 ton/ha $\mathrm{f}-\mathrm{MB}$ in soil, the release of $\mathrm{Cu}$ is expected to be $31.75 \mathrm{~kg} / \mathrm{ha}$ which is much lower than the risk limit of $\mathrm{Cu}$ in soil (112 kg/ha) reported by Spencer [44]. This method unveils promising insights upon the sustainability perspectives of agricultural impact under the context of circular economy.

\section{Results and Discussion}

\subsection{Adsorption Isotherms}

Langmuir and Freundlich were applied to examine the adsorption isotherms developed between the quantities of $\mathrm{PO}_{4}-\mathrm{P}$ sorption onto the $\mathrm{LMB}$ and $\mathrm{f}-\mathrm{MB}$ and the quantities of phosphate remaining in the aqueous phase.

The capacities of $\mathrm{PO}_{4}-\mathrm{P}$ adsorption on $\mathrm{LMB}$ and $\mathrm{f}-\mathrm{MB}$ at equilibrium are shown in Figures 2 and 3, as a function of the method of introducing the material into the aqueous solution (as teabag and as slurry). In Table 2 it is shown the Langmuir adsorption isotherms for $\mathrm{PO}_{4}-\mathrm{P}$ adsorption onto LMB and $\mathrm{f}-\mathrm{MB}$, revealing that the high regression coefficient $\left(\mathrm{R}^{2}\right)$ values implying the good matching of the Langmuir model to the experimental results. Moreover, the maximum phosphate adsorption capacities $\left(q_{m}\right)$ of LMB, being reported at the aforementioned model, were $11.28 \mathrm{mg} / \mathrm{g}$ (as slurry) and $7.80 \mathrm{mg} / \mathrm{g}$ (as teabag), respectively.

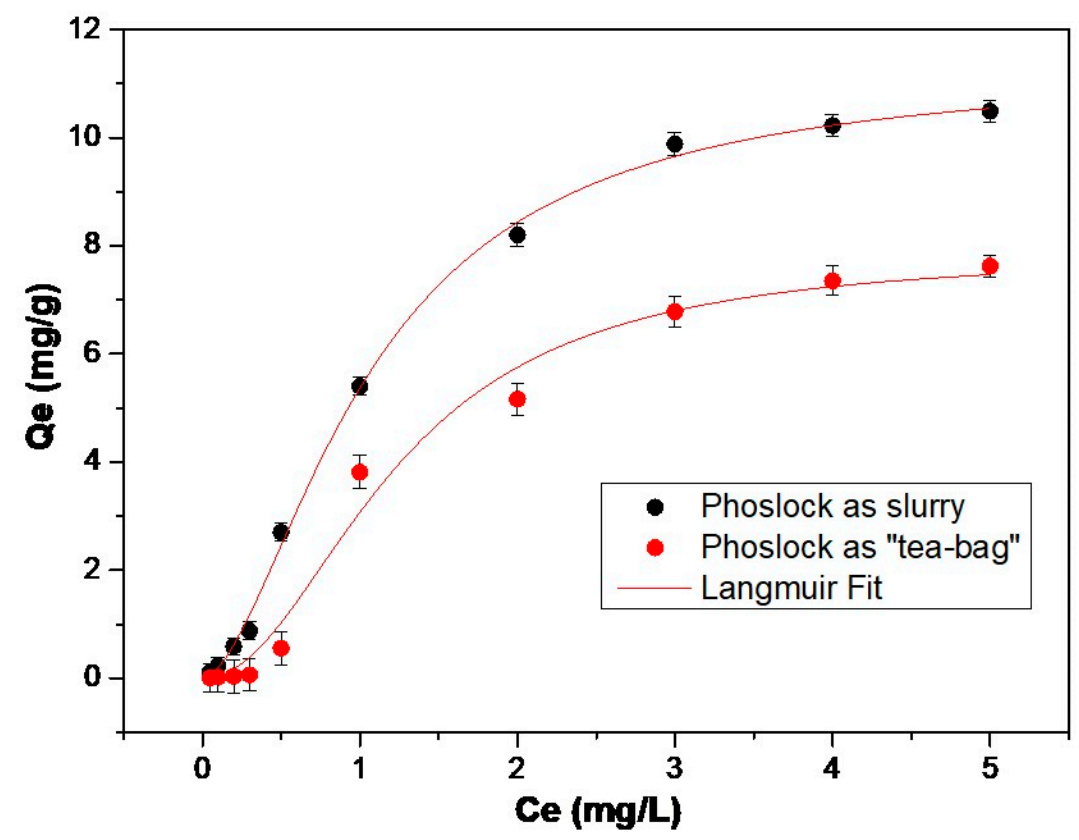

Figure 2. The adsorption isotherms and Langmuir, model fitting for phosphate-uptake by LMB as a slurry and as "teabag". Phosphate concentration $0.05-5 \mathrm{mg} / \mathrm{L}$, adsorbent dose $0.02 \mathrm{~g}, \mathrm{pH}=7.0$, $\mathrm{T}=25^{\circ} \mathrm{C}$. 


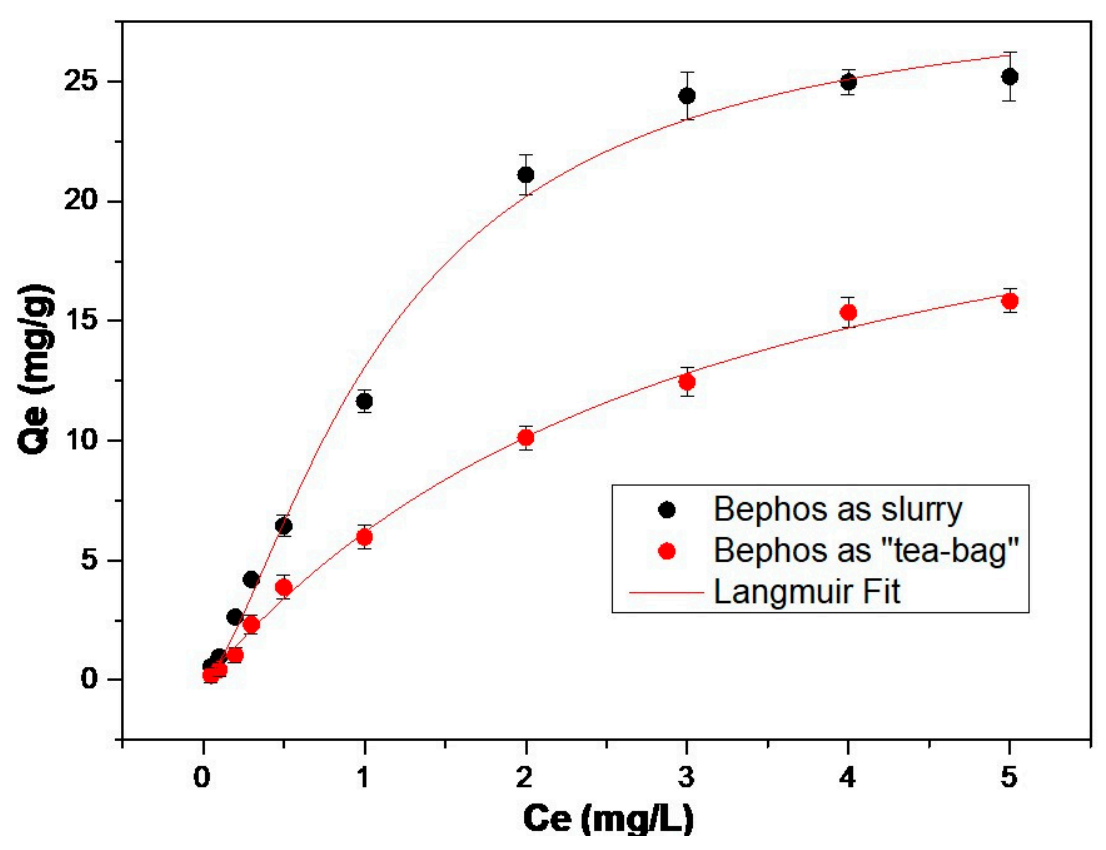

Figure 3. The adsorption isotherms and Langmuir, model fitting for phosphate-uptake by Fe-modified bentonite (f-MB) as a slurry and as "teabag". Phosphate concentration $0.05-5 \mathrm{mg} / \mathrm{L}$, adsorbent dose $0.02 \mathrm{~g}, \mathrm{pH}=7.0, \mathrm{~T}=25^{\circ} \mathrm{C}$.

Table 2. The constants of Langmuir, for adsorption of phosphate on modified bentonites lanthanum-modified bentonite (LMB) and f-MB.

\begin{tabular}{ccccc}
\hline Model & & Parameter & As a Slurry & As “Teabag" \\
\hline \multirow{2}{*}{ Langmuir } & \multirow{2}{*}{ LMB } & qm [mg/gr] & 11.28 & 7.80 \\
Equation & $\mathrm{b}$ & 0.9 & 0.6 \\
& & $\mathrm{R} 2$ & 0.99 & 0.6 \\
\hline \multirow{2}{*}{ Langmuir } & \multirow{2}{*}{ f-MB } & $\mathrm{qm}[\mathrm{mg} / \mathrm{gr}]$ & 28.9 & 25.1 \\
Equation & $\mathrm{b}$ & 0.8 & 0.3 \\
& & $\mathrm{R} 2$ & 0.99 & 0.99 \\
\hline
\end{tabular}

The isotherms showed a sharp increase of adsorption capacity with the concentration of the equilibrium solution (0.05-3 mg/L, Figure 2), followed by a plateau (less significant phosphate uptake) at equilibrium (3-5 mg/L, Figure 2), thus verifying a typical Langmuir isotherm reported at other studies $[7,45]$. In this type of isotherm, the initial slope does not significantly change with the increase of the solute concentration. In addition, Figure 3 shows the equilibrium adsorption capacities of $\mathrm{PO}_{4}-\mathrm{P}$ onto $\mathrm{f}-\mathrm{MB}$ as a function of the method of introducing the material into the aqueous solution (as teabag and as slurry). The maximum phosphate adsorption capacities $\left(q_{m}\right)$ of $\mathrm{f}-\mathrm{MB}$, being reported at the Langmuir adsorption isotherms model, were $28.9 \mathrm{mg} / \mathrm{g}$ and $25.1 \mathrm{mg} / \mathrm{g}$, respectively.

\subsection{Adsorption Kinetics}

Adsorption kinetic data of phosphate on the modified bentonites LMB and FMB are presented in Figures 4 and 5. The plots depict the adsorption of $\mathrm{PO}_{4}-\mathrm{P}$ onto $\mathrm{LMB}$ and f-MB versus contact time ranging from 15 to $240 \mathrm{~min}(4 \mathrm{~h})$, as a function of the method of introducing the material into the aqueous solution (as teabag and as slurry). Figure 4 unveils that most of $\mathrm{PO}_{4}-\mathrm{P}$ was adsorbed during the first $60 \mathrm{~min}$ of application, whereas upon contact time running, the removal rate is considerably decreased; after time running of $180 \mathrm{~min}$ the removal rate is almost negligible. In time running of approximately $60 \mathrm{~min}$ of adsorption, then, sorption equilibrium begins to establish. It is important to signify that the adsorption rate of phosphate onto both innovative materials did not differ depending 
on the method of application into the aqueous solution. This sorption behavior is consistent to literature findings from other studies where the initially high adsorption experimental rates are attributed to a rapid coverage of active sites (that is boundary layer diffusion), while intra-particle diffusion processes are responsible for a time-running gradual decrease reported [12]. Yet in the case of teabags the particles need to diffuse first inside the bag to reach the active sites of the materials, showing a delay in the kinetic, especially in the first minutes of the binding.

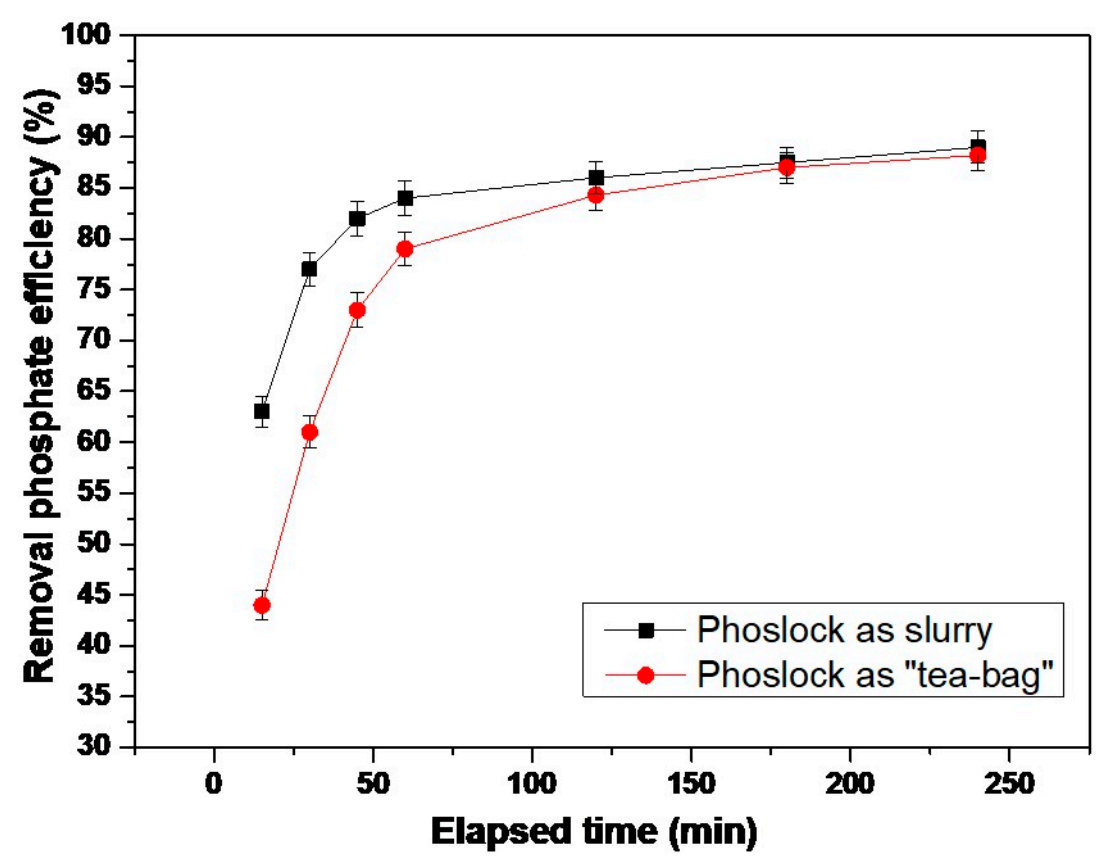

Figure 4. Adsorption kinetics of phosphate uptake by LMB. (black symbols LMB as a slurry and red symbols as "teabag"). Phosphate concentration $0.1 \mathrm{mg} / \mathrm{L}$, adsorbent dose $0.02 \mathrm{~g}, \mathrm{pH}=7.0, \mathrm{~T}=25^{\circ} \mathrm{C}$.

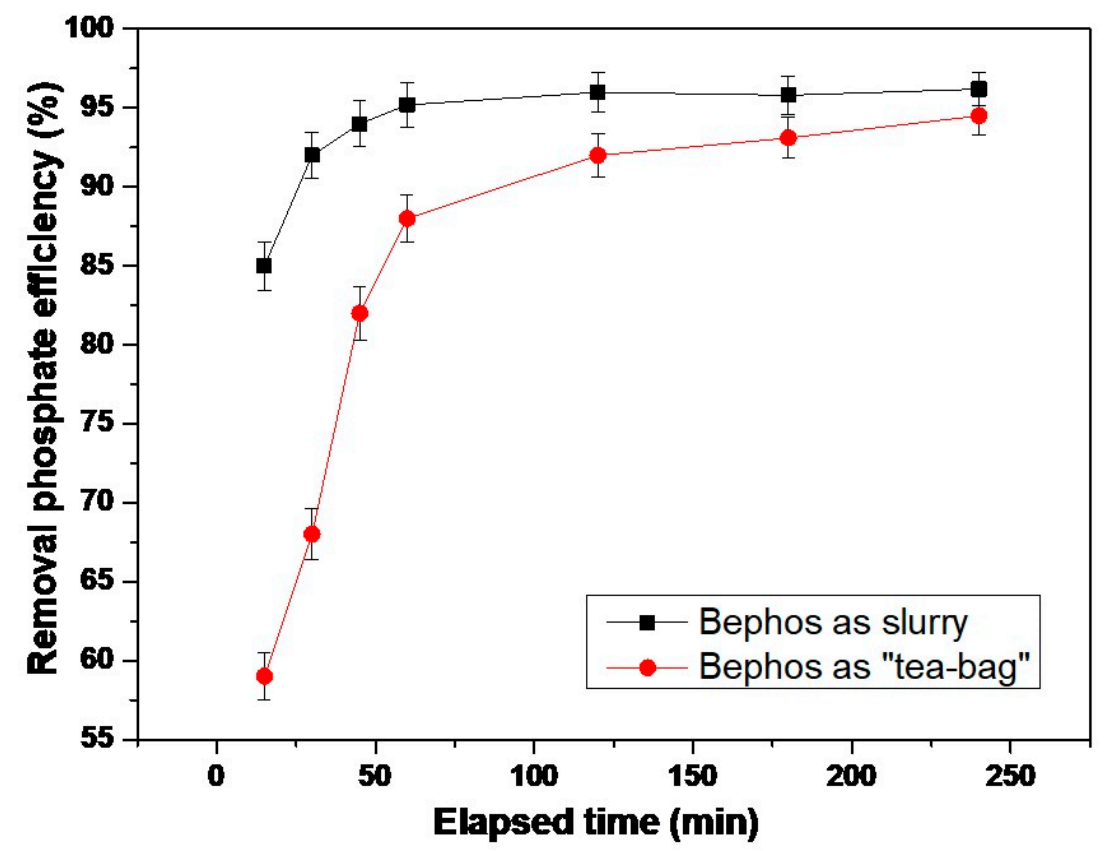

Figure 5. Adsorption kinetics of phosphate uptake by f-MB. (black symbols f-MB as a slurry and red symbols as "teabag"). Phosphate concentration $0.1 \mathrm{mg} / \mathrm{L}$, adsorbent dose $0.02 \mathrm{~g}, \mathrm{pH}=7.0, \mathrm{~T}=25^{\circ} \mathrm{C}$. 
Therefore, even though it seems that the adsorption capacity of the materials in tea bags is reduced, this is not the case, since tea bags are acting as a filter that mechanically slows down the kinetic of the binding, moving the equilibrium time to more than three hours. This delay is more pronounced in the case of $\mathrm{f}-\mathrm{MB}$ possibly due to structural differences between $\mathrm{f}-\mathrm{MB}$ and LMB.

Like reported previously in the adsorption isotherms (Figures 2 and 3) it is evident from the kinetics that tea bags are mechanically delaying the adsorption, moving the equilibrium time from $3 \mathrm{~h}$ to more than 4 , especially in $\mathrm{f}-\mathrm{MB}$ which has a higher total adsorption capacity.

\subsection{Aging of $L M B$ and $f-M B$}

Figure 6 shows the percentage of phosphate that remains adsorbed onto f-MB (Figure 6a) and LMB (Figure $6 \mathrm{~b}$ ), respectively, during a period of 6 months. According to Figure $6 \mathrm{a}, \mathrm{b}$ no more than $26 \%$ and $23 \%$ of the initially adsorbed phosphate ions $\left(\mathrm{PO}_{4}-\mathrm{P}\right)$ re-diffused into aqueous solution, approximately at the time period of $\sim 60$ days after application. This indicates the suspension of large quantities of phosphates onto LMB and f-MB for a long time, thus supporting materials' reuse of material at in-field applications. Moreover, the study of aging is very important because it allows us to precisely estimate the time when phosphorus desorption begins. Therefore, knowing the residence time of the material in the water column by applying the teabag method, enable us to uptake the optimum P-contained material for further fertilizing applications.
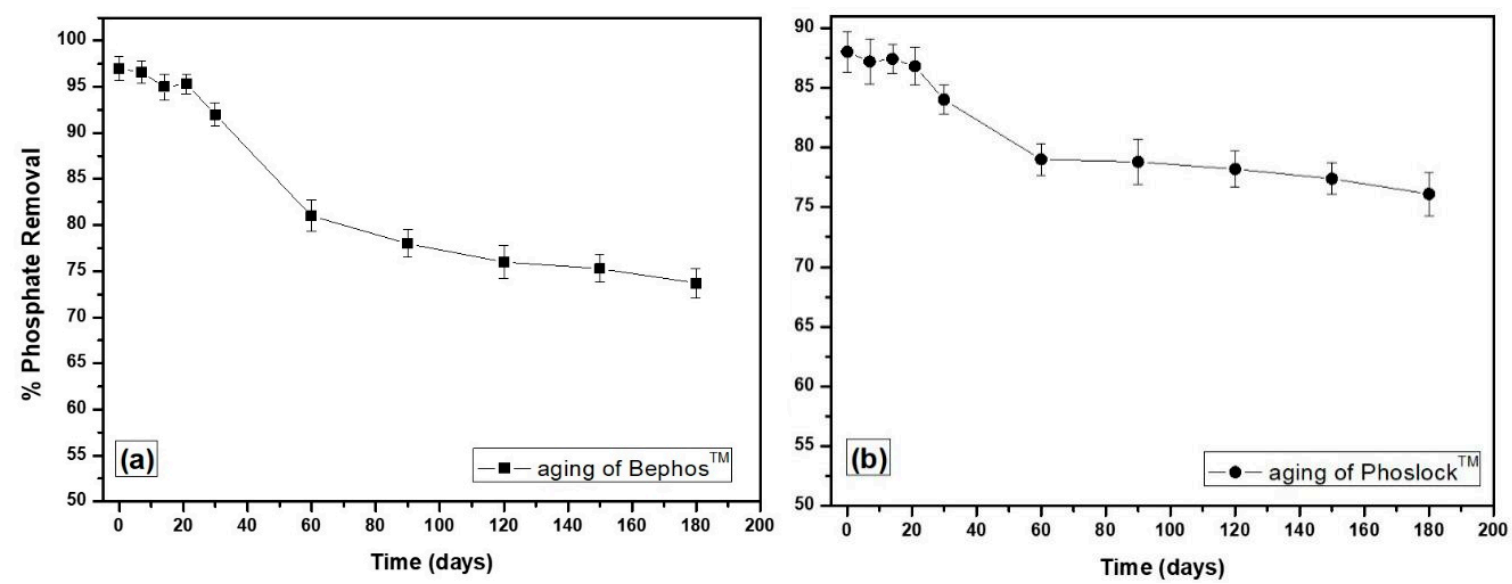

Figure 6. (a) Aging of f-MB, (b) Aging of LMB.

\subsection{Turbidity}

The effect of LMB and f-MB slurry and teabag applications on turbidity showed the following behavior: At the time of initial application, turbidity was initially increased for both agents and after time running it was reported a gradual decrease on turbidity of aqueous solutions, reaching a 40 NTU for LMB for an elapsed time of $1 \mathrm{~h}$ (Figure 7) and a $15 \mathrm{NTU}$ for f-MB for an elapsed time of $1 \mathrm{~h}$ (Figure 8), accordingly. Moreover, Bephos slurry is causing lower turbidity at the water body, since it settles faster due to its composite structure, comparing to that of LMB. It is further noteworthy that both LMB (Figure 7) and f-MB (Figure 8)—being packed in the "teabag" form—are causing lower turbidity in water, since in this format both materials are not suspended in the aqueous solutions, accordingly.

An application of LMB will initially increase turbidity followed by a and gradually decrease on turbidity. In a field application scenario LMB, due to its rapid settlement, would not cause prolonged light limitation for submerged macrophytes. The aforementioned behavior of turbidity, Figures 7 and 8, is verified by the relevant literature [46]. At this study, [46] authors denoted that the Lanthanum Modified Bentonite (LMB) application in Lake Rauwbraken (The Netherlands) strongly reduced turbidity along with other critical parameters such as: the water column chlorophyll-a concentration, the share of cyanobacteria, total phosphorus and nitrogen concentrations and 
filterable phosphorus concentration. Contrarily, it increased Secchi depth and hypolimnetic oxygen concentration/saturation [46]. In fact, application of any submerged material would increase turbidity but only for a short time, yet in the long term, due to phosphate removal and phytoplankton biomass reduction, a decrease in turbidity is expected, with its overall positive effect on the studied ecosystem.

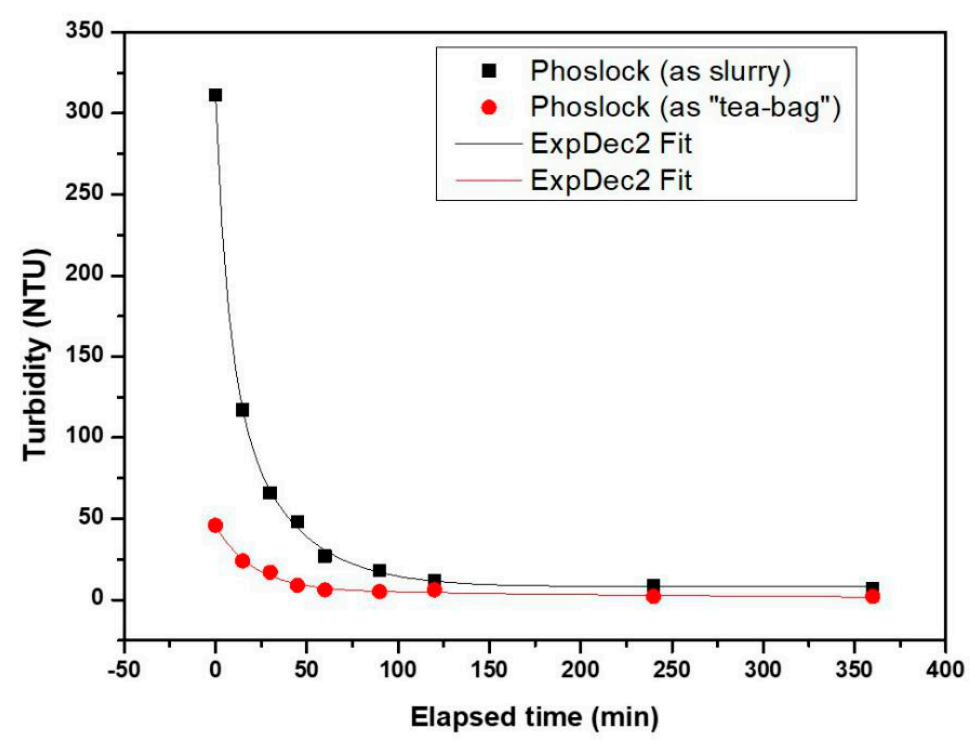

Figure 7. Turbidity after LMB application.

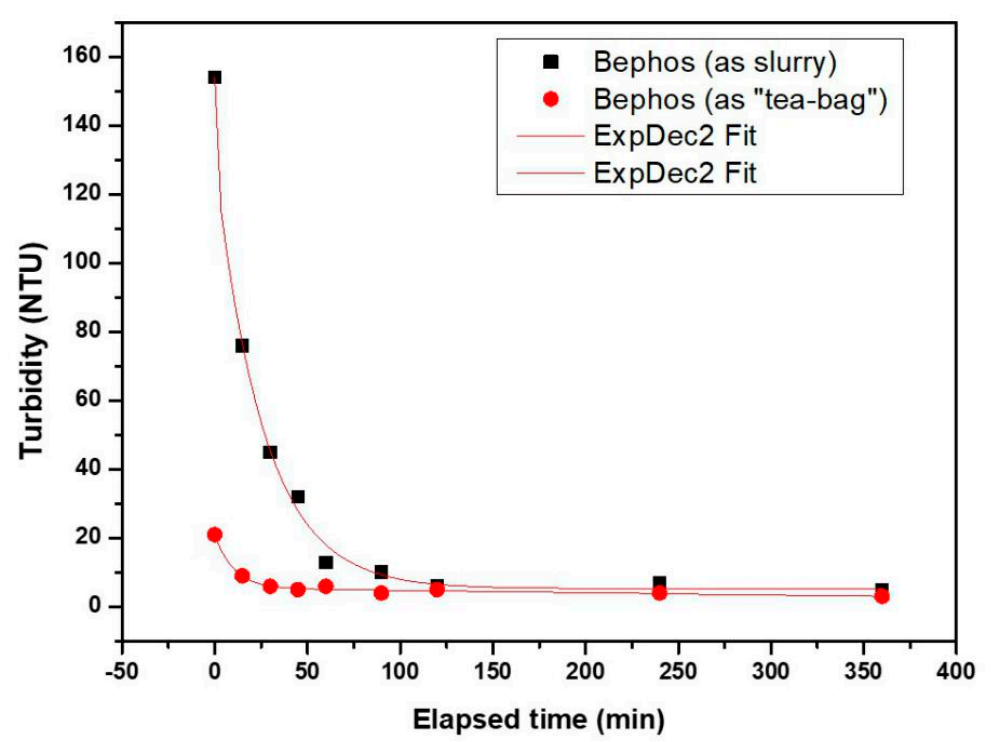

Figure 8. Turbidity after f-MB application.

\subsection{Challenging Issues of Novel Composite Materials in The Direction of Ecology and Circular Economy (CE)}

Composite material f-MB can restrain the sedimentary P release, reduce the P-mobile in sediments, increase the "apatite bound $\mathrm{P}$ " fraction compared to P-mobile, and dispose more $\mathrm{P}$ storage in the residual $\mathrm{P}$ fraction of sediment post-application. Fe-modified bentonite $\mathrm{f}-\mathrm{MB}$ can achieve up to $96.6 \%$ reduction of the phosphate flux, as well as $75.2 \%$ reduction of sedimentary ammonium flux [11]. Generally, it has been reported that the use of $\mathrm{P}$ inactivating agents for lake restoration can reduce the internal P loading from sediment, regardless that the physicochemical properties of $P$ inactivating agents are mainly determined by a wide spectrum of environmental factors' involved to different control and risks' planning, thus necessitating detailed investigation of each one agent before application [45]. 
Therefore, this study was focused on challenges and methodologies to improve P use efficiency and sustainability in the environment. In this framework, technologies for the removal of P-containing compounds from water using functional sorbents should mainly regard surface properties for capture and removal, through recycling the LMB and f-MB materials as alternative soil fertilizers.

Smothering of benthos and accumulation of sediments-being related to, first, the deposition of layers of sediment on the seabed and, secondly, the depth of vertical overburden (mainly associated with trophic group and particle size/sediment type, [47]—can be directly affected by both the sea disposal of dredged materials and by the application of capping materials. Therefore, the profile of benthic organisms is determined by the suspensions that can be deliberately deposited on the seabed and by the marine biota to be able (or unable) to adapt, e.g., sessile organisms are obscured to make their way to the surface. Particularly, most benthic organisms lives in the top $10 \mathrm{~cm}$ of the seabed, thus, they sustain their ventilation and feeding needs by maintaining some connection to the sediment-water interface [48].

The aforementioned effects are also mediated by the thickness of deposition and the intensity and frequency of deposition events. Many species are adapted to re-surface from thin deposits, but the intense deposition events are considered a substantial burden on the ecosystem. Therefore, the application process of P-inactivation agents in a natural and dynamic ecosystem requires careful consideration (Figure 9a). The necessary quantities of material utilized in the form of slurry should be accurately calculated, being based on the potentially bioavailable mobile $\mathrm{P}$ of the sediment in the water column (Figure 9b) [45,49-51] present in the water column and its external flows can be adsorbed by the proposed method of "tea-bag" (Figure 9c,d).

Such a method applied can achieve a substantial decrease of the, otherwise, excessive quantity of the materials disposed in natural eutrophic waters. In this case, after extensive monitoring of the ecosystem (internal P-loads, bathymetry, etc.) we can introduce the P-inactivation agents in the water column by the method of "teabag" adsorbing the available inorganic P from water body. Innovative materials can be attached to buoys at different depths to absorb the available phosphorus remaining in the water column without creating a risk for the ecosystem (Figure 9d). The amount of materials per bag will depend on the concentration of phosphorus in the water column, the spatial points of main P external inputs, and the total volume of the lake/pond/reservoir. However, experimental results showed that LMB and Bephos ${ }^{\mathrm{TM}}$ sustained a maximum adsorption capacity of $7.80 \mathrm{mg} / \mathrm{g}$ and $25.1 \mathrm{mg} / \mathrm{g}$, respectively, which is sufficient for $\mathrm{P}$ concentrations reported in natural aquatic ecosystems (Figures 2 and 3).

At the same time this new method did not cause turbidity (Figures 7 and 8) in the water column as the material was not released into the water avoiding potential harmful consequences for the living organisms. After the period of residence of the materials in the water ( 60 days, as aforementioned) (Figure 9d) the bags were removed from the water column and collected for further applicability as a soil improver or fertilizer in crops. The possibility to recycle LMB and Bephos ${ }^{\mathrm{TM}}$ materials for agricultural use is of paramount importance. These materials are clay-based, so their addition to soil does not disturb the ecosystem but can improve its cation exchange capacity (CEC) [49]. Moreover, $\mathrm{f}-\mathrm{MB}$ contain also monovalent iron and copper that could act like micronutrients. However, the most advantageous feature of $\mathrm{f}-\mathrm{MB}$ is its ability to retardedly adsorb phosphorous and, then slowly release it (Figure 6a). Specifically, it has been reported that Bephos ${ }^{\text {TM }}$ can uptake $26.5 \mathrm{~g} \mathrm{~kg}^{-1}$ phosphate, gradually releasing $5.3 \mathrm{~g} \mathrm{~kg}^{-1}$ every 6 months [11,12].

Considering the need of phosphorous in crop fields that is $\sim 50 \mathrm{~kg} \mathrm{ha}^{-1}$ per year (for the crops of wheat, maize and tomato), it was estimated that the need of $5 \mathrm{tn} \mathrm{ha}{ }^{-1}$ of $\mathrm{f}-\mathrm{MB}$ would retardedly release the necessary phosphorus over the aforementioned phosphate-release rate. $\mathrm{f}-\mathrm{MB}$ is not merely a modified clay, but it can be considered as a modified organo-mineral clay, since it contains humic acid [51]. The application of $5 \mathrm{tn} \mathrm{ha}^{-1} \mathrm{f}-\mathrm{MB}$ in the field could result in the addition of $6 \mathrm{~kg} \mathrm{ha}^{-1}$ humic acid. However, the overall evaluation of the use of such composite materials as fertilizers will be assessed in a forthcoming publication. 

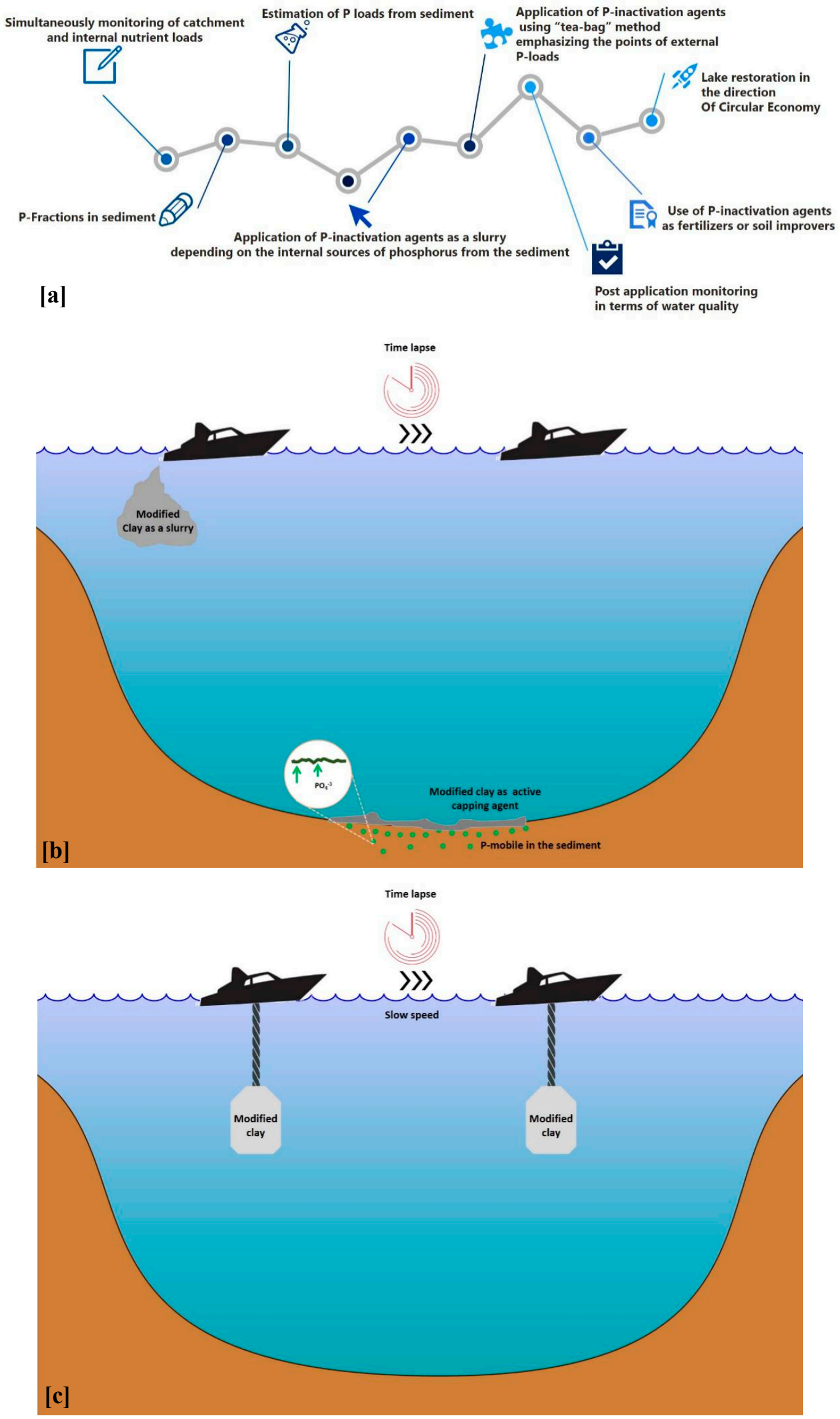

Figure 9. Cont. 


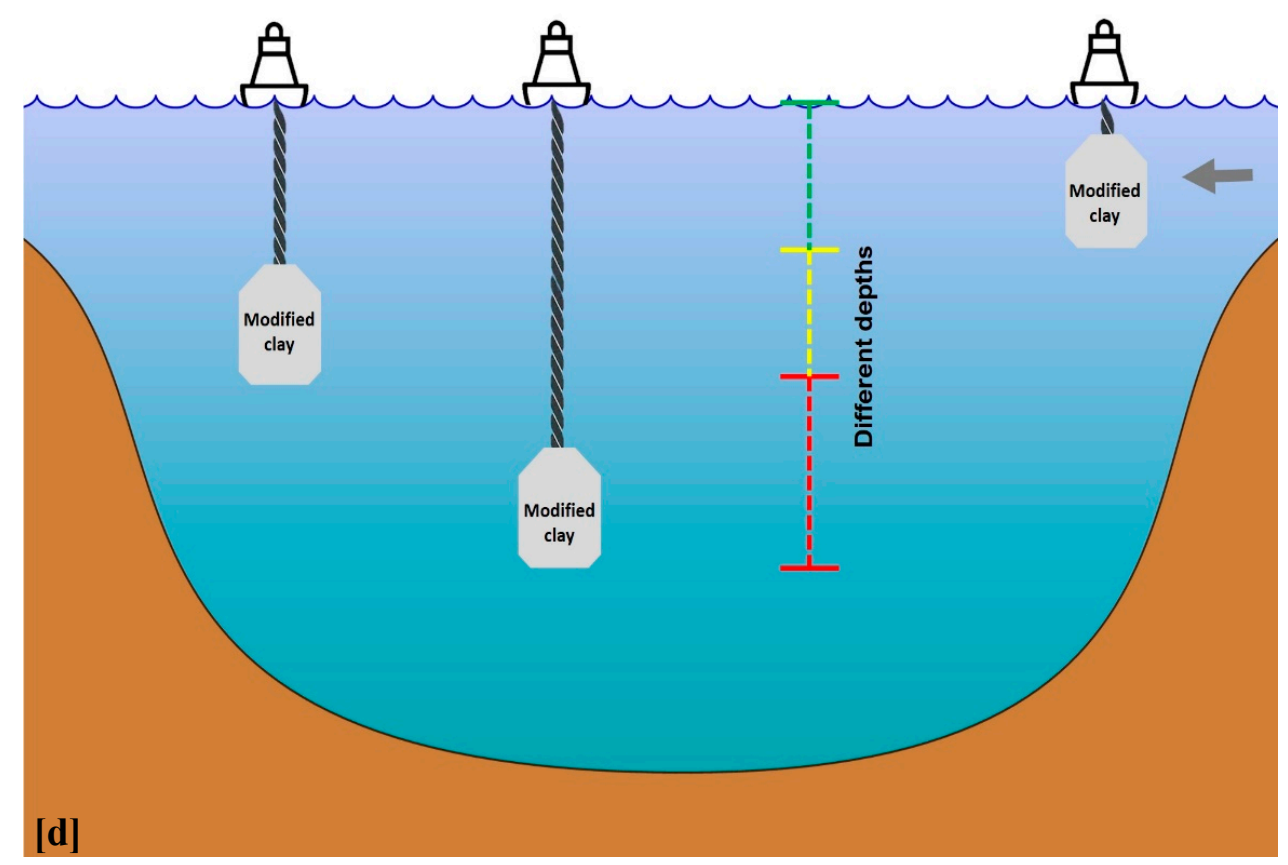

Figure 9. Application process of P-inactivation agents in the context of an integrated approach to eutrophication management. (a) Conceptual model of P-inactivation agents application in a natural and dynamic ecosystem, (b) The necessary quantities of material utilized in the form of slurry should be accurately calculated, being based on the potentially bioavailable mobile P of the sediment in the water column (c,d) The use of tea-bag method to adsorb bioavailable P from external flows.

\section{Conclusions}

According to the analysis above the main research outcomes are critically represented at Table 3 , below. Based on Table 3 the research outcomes were evaluated in terms of weighted indicators. It can be signified that the proposed method of eutrophic waters remediation is mostly advantageous from an environmental viewpoint, followed by a promising developmental perspective at the contexts of materials used and economics performance. The reason of this moderate materials' and economics' performance resides to the fact of, having no accumulated extensive practical applicability by other well reported and already running applications. However, the joint co-evaluation of Bephos ${ }^{\mathrm{TM}}$ and LMB is offering a better control over the slurry quantities finally disposed to eutrophic water sources. The necessary quantities of material utilized in the form of slurry are accurately calculated, on the mobile $\mathrm{P}$ of the sediment potentially bioavailable in the water column. P presented in the water column and its external flows can be adsorbed by the proposed "tea bag" method.

Table 3. Evaluation profile of the method developed. Source: authors' own study.

\begin{tabular}{cccc}
\hline Key-Aspects of Future Development & Material & Environment & Economy \\
\hline Technological maturity/Industrial scalability & ++ & + & + \\
\hline Technical adaptability to other techniques of environmental remediation & +++ & +++ & ++ \\
\hline Ecosystems' protection and sustainability & + & +++ & ++ \\
\hline Economic scalability & + & +++ & ++ \\
\hline
\end{tabular}

Scale of weighted indicators: + : low positive, ++ : fairly positive, +++ : highly positive.

Such an applied method can achieve a substantial reduce of slurry quantity, being related to the sediments' bound P. The environmental remediation of natural aquatic systems was accomplished by the sorption of phosphates to precisely calculated quantities of modified composite Fe-bentonite, $\mathrm{f}-\mathrm{MB}$ and Lanthanum modified bentonite, LMB where the generated "teabag" product can be further used as fertilizer. Moreover, conservation of natural mineral resources-such as phosphorus-is 
achieved, since phosphate fertilizers cay be produced by composite materials. Finally, the technological simplicity, the reasonable pricing of all materials involved and the high removal rates of phosphate achieved, all offer a promising applicability of the method proposed.

Author Contributions: G.L.K. and V.C.K. contributed to the deployment of the literature review, the structure of the research analysis, the discussion deployed and the conclusions drawn. M.D. contributed to the development of technical analysis, I.K.K. contributed in writing and remarks' clarification and M.Z. supervised the article. All authors have read and agreed to the published version of the manuscript.

Funding: This research received no external funding.

Conflicts of Interest: The authors declare no conflict of interest.

\section{References}

1. Lin, J.; Zhan, Y.; Zhu, Z. Evaluation of sediment capping with active barrier systems (ABS) using calcite/zeolite mixtures to simultaneously manage phosphorus and ammonium release. Sci. Total Environ. 2011, 409, 638-646. [CrossRef] [PubMed]

2. Nixon, S.W. Coastal marine eutrophication: A definition, social causes, and future concerns. Ophelia 1995, 41, 199-219. [CrossRef]

3. Solheim, A.L.; Rekolainen, S.; Moe, S.J.; Carvalho, L.; Phillips, G.; Ptacnik, R.; Penning, W.E.; Toth, L.G.; O'Toole, C.; Schartau, A.-K.L.; et al. Ecological Threshold Responses in European Lakes and Their Fpplicability for the Water Framework Directive (WFD) Implementation: Synthesis of Lakes Results from the REBECCA Project; Springer: Berlin/Heidelberg, Germany, 2008.

4. Kapsalis, V.C.; Kyriakopoulos, G.L.; Aravossis, K.G. Investigation of ecosystem services and circular economy interactions under an inter-organizational framework. Energies 2019, 12, 1734. [CrossRef]

5. Kyriakopoulos, G.L.; Kapsalis, V.C.; Aravossis, K.G.; Zamparas, M.; Mitsikas, A. Evaluating circular economy under a multi-parametric approach: A technological review. Sustainability 2019, 11, 6139. [CrossRef]

6. Hickey, C.W.; Gibbs, M.M. Lake sediment phosphorus release management-Decision support and risk assessment framework. New Zeal. J. Mar. Freshw. Res. 2009, 43, 819-856. [CrossRef]

7. Zamparas, M.; Gianni, A.; Stathi, P.; Deligiannakis, Y.; Zacharias, I. Removal of phosphate from natural waters using innovative modified bentonites. Appl. Clay Sci. 2012, 62-63, 101-106. [CrossRef]

8. Zamparas, M.; Zacharias, I. Restoration of eutrophic freshwater by managing internal nutrient loads. A review. Sci. Total Environ. 2014, 496, 551-562. [CrossRef]

9. Jeppesen, E.; Sondergaard, M.; Jensen, J.P.; Havens, K.E.; Anneville, O.; Carvalho, L.; Coveney, M.F.; Deneke, R.; Dokulil, M.T.; Foy, B.; et al. Lake responses to reduced nutrient loading-An analysis of contemporary long-term data from 35 case studies. Freshw. Biol. 2005, 50, 1747-1771. [CrossRef]

10. Kobetičová, K.; Černý, R. Terrestrial eutrophication of building materials and buildings: An emerging topic in environmental studies. Sci. Total Environ. 2019, 689, 1316-1328. [CrossRef]

11. Zamparas, M.; Drosos, M.; Deligiannakis, Y.; Zacharias, I. Eutrophication control using a novel bentonite humic-acid composite material Bephos ${ }^{\mathrm{TM}}$. J. Environ. Chem. Eng. 2015, 3, 3030-3036. [CrossRef]

12. Zamparas, M.; Drosos, M.; Georgiou, Y.; Deligiannakis, Y.; Zacharias, I. A novel bentonite-humic acid composite material Bephos ${ }^{\mathrm{TM}}$ for removal of phosphate and ammonium from eutrophic waters. Chem. Eng. J. 2013. [CrossRef]

13. Bishop, W.M.; McNabb, T.; Cormican, I.; Willis, B.E.; Hyde, S. Operational evaluation of Phoslock phosphorus locking technology in Laguna Niguel Lake, California. Water. Air. Soil Pollut. 2014, 225. [CrossRef]

14. Kasprzyk, M.; Obarska-Pempkowiak, H.; Masi, F.; Gajewska, M. Possibilities of Phoslock ${ }^{\circledR}$ application to remove phosphorus compounds from wastewater treated in hybrid wetlands. Ecol. Eng. 2018, 122, 84-90. [CrossRef]

15. Spears, B.M.; Lürling, M.; Yasseri, S.; Castro-Castellon, A.T.; Gibbs, M.; Meis, S.; McDonald, C.; McIntosh, J.; Sleep, D.; Van Oosterhout, F. Lake responses following lanthanum-modified bentonite clay (Phoslock ${ }^{\circledR}$ ) application: An analysis of water column lanthanum data from 16 case study lakes. Water Res. 2013, 15, 5930-5942. [CrossRef]

16. Haghseresht, F.; Wang, S.; Do, D.D. A novel lanthanum-modified bentonite, Phoslock, for phosphate removal from wastewaters. Appl. Clay Sci. 2009, 46, 369-375. [CrossRef] 
17. Liu, Y.; Tian, K.; Winks, A. Water eutrophication prevention by phoslock flocculation and sediment capping reaction. In Proceedings of the 2009 International Conference on Environmental Science and Information Application Technology, Wuhan, China, 4-5 July 2009.

18. Robb, M.; Greenop, B.; Goss, Z.; Douglas, G.; Adeney, J. Application of Phoslock ${ }^{\mathrm{TM}}$, an innovative phosphorus binding clay, to two Western Australian waterways: Preliminary findings. In Proceedings of the Hydrobiologia; Springer: Dordrecht, The Netherlands, 2003.

19. Silvenius, F.; Grönroos, J.; Kankainen, M.; Kurppa, S.; Mäkinen, T.; Vielma, J. Impact of feed raw material to climate and eutrophication impacts of Finnish rainbow trout farming and comparisons on climate impact and eutrophication between farmed and wild fish. J. Clean. Prod. 2017, 164, 1467-1473. [CrossRef]

20. Wang, S.; Yang, T.; Cheng, Y.; Zhang, H.; Wang, X.; Hu, H.; Ruan, X.; Fan, Z. Performance of two ornamental plants for purifying eutrophication materials in urban riverway sewages. In Proceedings of the 2011 International Conference on Electrical and Control Engineering, Yichang, China, 16-18 September 2011.

21. Yin, H.; Zhu, J.; Tang, W. Management of nitrogen and phosphorus internal loading from polluted river sediment using Phoslock $®$ and modified zeolite with intensive tubificid oligochaetes bioturbation. Chem. Eng. J. 2018, 353, 46-55. [CrossRef]

22. Bishop, W.M.; Richardson, R.J. Influence of Phoslock ${ }^{\circledR}$ on legacy phosphorus, nutrient ratios, and algal assemblage composition in hypereutrophic water resources. Environ. Sci. Pollut. Res. 2018, 25, 4544-4557. [CrossRef]

23. Liu, Y.; Tian, K.; Winks, A. Phoslock, a soluble phosphorus binding technology, application in Lake Dianchi eutrophic water purification. In Proceedings of the 2009 International Conference on Environmental Science and Information Application Technology, Wuhan, China, 4-5 July 2009.

24. Epe, T.S.; Finsterle, K.; Yasseri, S. Nine years of phosphorus management with lanthanum modified bentonite (Phoslock) in a eutrophic, shallow swimming lake in Germany. Lake Reserv. Manag. 2017, 33, 1-11. [CrossRef]

25. Nürnberg, G.K. Attempted management of cyanobacteria by Phoslock (lanthanum-modified clay) in Canadian lakes: Water quality results and predictions. Lake Reserv. Manag. 2017, 163-170. [CrossRef]

26. Spears, B.M.; Mackay, E.B.; Yasseri, S.; Gunn, I.D.M.; Waters, K.E.; Andrews, C.; Cole, S.; De Ville, M.; Kelly, A.; Meis, S.; et al. A meta-analysis of water quality and aquatic macrophyte responses in 18 lakes treated with lanthanum modified bentonite (Phoslock®). Water Res. 2016, 97, 111-121. [CrossRef] [PubMed]

27. Kasprzyk, M.; Gajewska, M. Preliminary results from application Phoslock®to remove phosphorus compounds from wastewater. J. Ecol. Eng. 2017, 18, 82-89.

28. Liu, Y.; Tian, K.; Winks, A. Phoslock®: An effective technology for effective dissolved phosphorus removal in extensive water bodies under a wide range of chemical conditions. In Proceedings of the 2009 3rd International Conference on Bioinformatics and Biomedical Engineering, Beijing, China, 11-13 June 2009.

29. van Oosterhout, F.; Lürling, M. The effect of phosphorus binding clay (Phoslock ${ }^{\circledR}$ ) in mitigating cyanobacterial nuisance: A laboratory study on the effects on water quality variables and plankton. Hydrobiologia 2013, 710, 265-277. [CrossRef]

30. Meis, S.; Spears, B.M.; Maberly, S.C.; Perkins, R.G. Assessing the mode of action of Phoslock ${ }^{\circledR}$ in the control of phosphorus release from the bed sediments in a shallow lake (Loch Flemington, UK). Water Res. 2013, 47, 4460-4473. [CrossRef]

31. Lürling, M.; van Oosterhout, F. Case study on the efficacy of a lanthanum-enriched clay (Phoslock $\left.{ }^{\circledR}\right)$ in controlling eutrophication in Lake Het Groene Eiland (The Netherlands). Hydrobiologia 2013, 710, $253-263$. [CrossRef]

32. Yamada-Ferraz, T.M.; Sueitt, A.P.E.; Oliveira, A.F.; Botta, C.M.R.; Fadini, P.S.; Nascimento, M.R.L.; Faria, B.M.; Mozeto, A.A. Assessment of Phoslock ${ }^{\circledR}$ application in a tropical eutrophic reservoir: An integrated evaluation from laboratory to field experiments. Environ. Technol. Innov. 2015, 4, 194-205. [CrossRef]

33. Ding, S.; Sun, Q.; Chen, X.; Liu, Q.; Wang, D.; Lin, J.; Zhang, C.; Tsang, D.C.W. Synergistic adsorption of phosphorus by iron in lanthanum modified bentonite (Phoslock ${ }^{\circledR}$ ): New insight into sediment phosphorus immobilization. Water Res. 2018, 32-43. [CrossRef]

34. Reitzel, K.; Andersen, F.T.; Egemose, S.; Jensen, H.S. Phosphate adsorption by lanthanum modified bentonite clay in fresh and brackish water. Water Res. 2013, 47, 2787-2796. [CrossRef]

35. Cozzolino, V.; Di Meo, V.; Piccolo, A. Impact of arbuscular mycorrhizal fungi applications on maize production and soil phosphorus availability. J. Geochemical Explor. 2013, 129, 40-44. [CrossRef] 
36. Meis, S.; Spears, B.M.; Maberly, S.C.; O’Malley, M.B.; Perkins, R.G. Sediment amendment with Phoslock ${ }^{\circledR}$ in Clatto Reservoir (Dundee, UK): Investigating changes in sediment elemental composition and phosphorus fractionation. J. Environ. Manag. 2012, 93, 185-193. [CrossRef]

37. Burska, D.; Pryputniewicz-Flis, D.; Bankowska-Sobczak, A.; Brenk, G.; Woszczyk, T. The Efficiency of P-Removal from Natural Waters with Sorbents Placed in Water Permeable Nonwovens. IOP Conf. Ser. Earth Environ. Sci. 2019, 362. [CrossRef]

38. Zamparas, M.; Deligiannakis, Y.; Zacharias, I. Phosphate adsorption from natural waters and evaluation of sediment capping using modified clays. Desalin. Water Treat. 2013, 51. [CrossRef]

39. Gianni, A.; Zamparas, M.; Papadas, I.T.; Kehayias, G.; Deligiannakis, Y.; Zacharias, I. Monitoring and Modeling of Metal Concentration Distributions in Anoxic Basins: Aitoliko Lagoon, Greece. Aquat. Geochemistry 2013, 19, 77-95. [CrossRef]

40. Bulut, E.; Özacar, M.; Şengil, I.A. Adsorption of malachite green onto bentonite: Equilibrium and kinetic studies and process design. Microporous Mesoporous Mater. 2008, 115, 234-246. [CrossRef]

41. Su, J.; Huang, H.-G.; Jin, X.-Y.; Lu, X.-Q.; Chen, Z.-L. Synthesis, characterization and kinetic of a surfactant-modified bentonite used to remove $\mathrm{As}(\mathrm{III})$ and $\mathrm{As}(\mathrm{V})$ from aqueous solution. J. Hazard. Mater. 2011, 185, 63-70. [CrossRef]

42. Drosos, M.; Jerzykiewicz, M.; Deligiannakis, Y. H-binding groups in lignite vs. soil humic acids: NICA-Donnan and spectroscopic parameters. J. Colloid Interface Sci. 2009, 332, 78-84. [CrossRef]

43. Drosos, M.; Leenheer, J.A.; Avgeropoulos, A.; Deligiannakis, Y. H-binding of size- and polarity-fractionated soil and lignite humic acids after removal of metal and ash components. Environ. Sci. Pollut. Res. Int. 2014, 21, 3963-3971. [CrossRef]

44. Spencer, W.F. A Rapid Test for Possible Excesses of Copper in Sandy Soils, 544th ed.; University of Florida: Gainesville, FL, USA, 1954.

45. Zamparas, M.; Drosos, M.; Kalavrouziotis, I.K. Sorption of phosphate from innovative composite material focusing on physicochemical interactions. Desalin. WATER Treat. 2019, 151, 212-218. [CrossRef]

46. van Oosterhout, F.; Waajen, G.; Yasseri, S.; Manzi Marinho, M.; Pessoa Noyma, N.; Mucci, M.; Douglas, G.; Lürling, M. Lanthanum in Water, Sediment, Macrophytes and chironomid larvae following application of Lanthanum modified bentonite to lake Rauwbraken (The Netherlands). Sci. Total Environ. 2020, 706, 135118. [CrossRef]

47. Miller, D.C.; Muir, C.L.; Hauser, O.A. Detrimental effects of sedimentation on marine benthos: What can be learned from natural processes and rates? Ecol. Eng. 2002, 19, 211-232. [CrossRef]

48. Bolam, S.G.; Barrio-Frojan, C.R.S.; Eggleton, J.D. Macrofaunal production along the UK continental shelf. J. Sea Res. 2010, 64, 166-179. [CrossRef]

49. Zamparas, M.; Kyriakopoulos, G.L.; Kapsalis, V.C.; Drosos, M.; Kalavrouziotis, I.K. Application of novel composite materials as sediment capping agents: Column experiments and modelling. Desalin. Water Treat. 2019, 170, 111-118. [CrossRef]

50. Zamparas, M.; Gavriil, G.; Coutelieris, F.A.; Zacharias, I. A theoretical and experimental study on the P-adsorption capacity of Phoslock ${ }^{\mathrm{TM}}$. Appl. Surf. Sci. 2015, 335, 147-152. [CrossRef]

51. Zamparas, M.; Kapsalis, V.C.; Kanteraki, A.E.; Vardoulakis, E.; Kyriakopoulos, G.L.; Drosos, M.; Kalavrouziotis, I.K. Novel composite materials as P-adsorption agents and their potential application as fertilizers. Glob. Nest J. 2019, 21, 48-57.

C 2020 by the authors. Licensee MDPI, Basel, Switzerland. This article is an open access article distributed under the terms and conditions of the Creative Commons Attribution (CC BY) license (http://creativecommons.org/licenses/by/4.0/). 